\title{
Guts, no glory
}

Cite as: CMAJ 2022 February 7;194:E172-3. doi: 10.1503/cmaj.211548

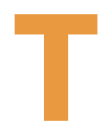

he clock shows 3:18. It hasn't read anything different all week. It's a tacky black and white clock, like you find in a dollar store, complete with dead batteries. Where is the nurse? I think it is my fifth night here, or is it my sixth? It doesn't really matter. I haven't left my room since I was admitted. I've barely even left my bed. Finally, the door swings open and the much-too-bright hospital light rushes in. Footsteps are accompanied by the rattle of my pain pills. The wound on my stomach throbs. I resist the urge to open my eyes. Every time I look at my stomach, I feel like I'm going to puke. If I keep them closed long enough, maybe I'll wake up at home.

$$
\text { ** * }
$$

Another time, another place, I wake in total darkness. The rustle of the palm trees outside reminds me l'm not in New Brunswick. My stomach immediately begins to grumble. My younger brother remains sound asleep, his chest rising and falling in an annoyingly satisfying rhythm. I am tempted to wake him. It would be a childish move for a grade 12 student, but why should I be the only one unable to sleep? It is the fourth time tonight l've had to use the bathroom. I crawl out of my bed and head toward the bathroom, passing my parents' bedroom on tiptoes. I stub my toe, hard, and it takes everything in me to stifle a scream. I continue down the hall and flick on the bathroom light. Damn, no toilet paper! I tighten my butt cheeks. My brain knows from experience that I have about 45 seconds before there is going to be a very large mess. I am now very much awake. Where would I keep extra toilet paper if I owned a Florida beach house? I check under the sink. Nope. I look over my shoulder toward the storage closet. No dice. I rush down a flight of stairs, three at a time, to the bathroom connected to my sister's room. I swing open the door and sit on the toilet just as time runs out.

$$
\star \star \star
$$

I try and catch my breath as a combination of blood, diarrhea and mucous violently leaves my body. I'm nearly certain that the frightening sounds echoing off the toilet's sides are reaching the university's largest lecture theatre next door. For most of my undergraduate lectures, I have tried to sit on its left side, about one-third of the way back, always on the aisle - a necessity for quick getaways. This time, I didn't give myself enough time to get to my favourite washroom: a private toilet on the fourth floor. I know the exact location of all the best (read: cleanest and most isolated) bathrooms on campus. I grimace in pain as my bowels gear up for the inevitable second wave. Oh my god, it feels like someone is stabbing me in the stomach. A second explosion reverberates through the stalls. I nervously glance at my phone; there are three minutes left in the lecture. My laptop is sitting unattended in the auditorium. I reach for the roll of toilet paper, and my eyes happen to glance down toward my black Calvin Klein underwear. My cheeks flush as I reach for the emergency pair of underwear hidden in the front compartment of my backpack. My heart sinks. Where's my backpack? I close my eyes and see it lying on the lecture hall floor, on the left side, about one-third of the way back, in front of the aisle seat.

The car horn blares a third time; I sling my backpack over my shoulder and climb in. This backpack is my ulcerative colitis lifeline. Now, as a university senior, I never leave home without it. Every medication bottle, granola bar and extra article of clothing has its particular place. I can navigate it in my sleep; sometimes I need to. I sit in the back seat, absolutely freezing in mid-January. The car's heater is as functional as my large intestine. At least I have a ride, because walking to the laboratory means 20 minutes with no access to a bathroom. I arrive and feel the urge to call my mom, as I have many times over the last four years. I missed a whole month of classes in my first year because of a flare-up. Then I battled an infection with Clostridium difficile. I was on high-dose prednisone for 19 months with all the adverse effects. I lost 16 percent of my body weight. I tried five different biologic medications before finding one that kept things under a semblance of control. How many hours on the toilet and in hospital waiting rooms? More missed parties than I can count. But now I am finishing an honours thesis. And, despite everything working against me, I have one medical school admission letter. I look out the window just in time to see the sun breaking through the clouds.

$$
\text { ** * }
$$

The afternoon sun peaks through the skylight on the roof of the auditorium. The class is getting restless; my mind is also roaming. I knew completing medical school with a chronic illness would be brutal. I'm grateful that my latest medication has held for two years, but now, its efficacy is starting to wane. I flash back to that terrible infection I had as an undergraduate. I won't let things get that bad again. But my options are limited. Do I bite the bullet and consent to a bowel resection, or do I try biologic number six? I've been dismissing the 
idea of an operation for the last five years, always hopeful that the next drug would be "the one." When does one know enough is enough? Medical school is demanding on a whole new level and the fatigue is wearing me out. How can I take care of other people if I can't take care of myself? Doctors make a lot of sacrifices - I wonder how many have sacrificed organs.

$$
\text { *** }
$$

I realize someone is trying to talk to me. It's the anesthetist. He asks me to count down from 100. I know most people don't make it past 90 . I have 10 conscious seconds left with my large intestine. The monitors behind me are beeping with every pump of my heart. I can't keep my eyes open anymore. There is no going back now.

My eyes flicker open. The pain is unfathomable - but I know it can be managed. Today is day five of my new life without a colon. Or is it day six? No matter, it must be almost time for the nurse to bring me my next dose of hydromorphone. My recovery has been slow, but for the first time in years, I feel myself think- ing about the future instead of hanging on to the past. I look down at my abdomen. Every time I look, I have been able to hold my gaze a little bit longer than the time before. My attention immediately goes to the part of my small intestine poking out through my skin, a stoma. I remember learning about them in class, but the textbooks did not have this view. I look up toward the clock on the wall, still stuck at 3:18. Next time I see the nurse, I'll ask about getting those batteries replaced.

\section{Jack Kerr BSC}

Faculty of Medicine, Memorial University, St. John's, Nfld.

This article has been peer reviewed.

This is a true story.

Author's note: This narrative would not have been possible without the exceptional support of Dr. Paul Moorehead. His enthusiasm, knowledge, attention to detail and insightful comments were incredibly helpful.

Content licence: This is an Open Access article distributed in accordance with the terms of the Creative Commons Attribution (CC BY-NC-ND 4.0) licence, which permits use, distribution and reproduction in any medium, provided that the original publication is properly cited, the use is noncommercial (i.e., research or educational use), and no modifications or adaptations are made. See: https://creativecommons.org/ licenses/by-nc-nd/4.0/ 